\title{
COMPLICATIONS OF CARDIAC INVESTIGATION
}

\author{
BY \\ A. W. VENABLES AND H. G. HILLER \\ From the Cardiac Investigatory Clinic and the Department of Radiology, Royal Children's Hospital, Melbourne, \\ Australia
}

Received August 20, 1962

There are many possible complications of cardiac catheterization and the studies associated with that procedure. These complications fall into three groups. There are those related simply to the passage of the catheter, those due to the injection of various substances as part of the procedure, and those due to accidental introduction of other undesirable elements into the cardiovascular system. Complications of premedication or of anæsthesia are omitted from this discussion.

The incidence of the various complications varies greatly. Stimulation of ectopic beats by the impact of the catheter on the ventricular endocardium is a regular and anticipated feature of cardiac catheterization. On the other hand knotting of the catheter inside the heart is an extremely rare event. The occurrence of many of the complications is unpredictable but may be catastrophic. Their incidence may well be an inverse function of the experience and skill of the investigator but equally at times merely represents local misfortune. The frequency of serious complications can probably only be judged from published mortality rates. In 1953 a committee of the American Heart Association (Cournand et al., 1953) recorded four deaths following catheterization in approximately 5700 procedures performed in eight laboratories: there were no deaths with 1325 angiograms reported by that committee. A Swedish survey published in 1959 (Bagger et al., 1957) recorded a mortality of 5 in 5859 right heart catheterizations: in 2958 angiographic studies there were 14 deaths. The mortality rate for right heart catheterization in both these reports is approximately one per thousand. Unfortunately no information is given regarding the types of case studied or the extent of catheterization procedures, but it can be assumed that many of these patients were adults with acquired heart diseases.

The incidence of serious complications in studies on patients with congenital heart disease is almost certainly much higher. Keith, Rowe, and Vlad (1958) record the mortality in such patients as 1.4 per cent under the age of 12 months with mortality in 800 patients of 0.63 per cent. Although increasing experience should make these procedures safer, the widening scope of such studies and the investigation of greater numbers of sick infants with congenital heart disease tend to increase the observed hazard. This is emphasized by the death of some infants before a scheduled investigation had been done.

At the Royal Children's Hospital, Melbourne, 837 cardiac catheterizations have been performed up to June 30,1962 . With these procedures there have been 431 injections of radio-opaque dye for selective angiography. Since 1954, when catheterization was commenced, 337 venous angiocardiograms have been performed. Very few of these were in recent years, the procedure having been replaced by selective angiocardiography. In addition a small number of retrograde catheterizations of the aorta and left heart have been performed. As these studies were carried out on patients presenting to a pædiatric unit dealing essentially with congenital heart disease the upper limit of age was 14 years, and most patients had or were suspected to have developmental anomalies 
of various types. Approximately 5 per cent of the patients catheterized were less than 6 months of age.

Since 1954, 6 patients have died as a direct result of these procedures. There were 2 deaths that resulted from severe arrhythmia precipitated by catheterization. Complications of injection of radio-opaque dye accounted for 4 deaths. In addition to the deaths recorded since 1954, in 1949 a child was found dead two hours after a venous angiocardiogram. This girl, aged 7 years,

TABLE I

\begin{tabular}{|c|c|c|c|c|}
\hline $\begin{array}{c}\text { Case } \\
\text { number }\end{array}$ & Age & Basic condition & Complication & Outcome \\
\hline \multicolumn{5}{|c|}{ A: Complications directly related to catheterization } \\
\hline 1 & $4 \mathrm{yr}$. & $\begin{array}{l}\text { V.S.D. }{ }^{1} \text { : P.D.A. } \\
\text { Pulmonary hypertension }\end{array}$ & Axillary vein thrombosis & Recovery \\
\hline 2 & $6 \mathrm{mth}$. & $\begin{array}{l}\text { P.V.S. }{ }^{3} \text { : P.F.O. } \\
\text { Right-to-left shunt }\end{array}$ & $\begin{array}{l}\text { Femoral vein thrombosis } \\
\text { Paradoxical cerebral embolism }\end{array}$ & $\begin{array}{l}\text { Permanent } \\
\text { hemiplegia }\end{array}$ \\
\hline 3 & 16 mth. & Fallot's tetrad & $\begin{array}{l}\text { Perforation of axillary vein } \\
\text { Dye extravasation }\end{array}$ & Recovery \\
\hline 4 & $13 \mathrm{yr}$. & V.S.D. ${ }^{1}$ : A.R. ${ }^{5}$ & $\begin{array}{l}\text { Perforation of iliac artery } \\
\text { Retroperitoneal hæmatoma }\end{array}$ & Recovery \\
\hline 5 & $5 \mathrm{yr}$. & Pulmonary atresia: V.S.D.1 & $\begin{array}{l}\text { Thrombocytopenia } \\
\text { Femoral artery hæmorrhage }\end{array}$ & Recovery \\
\hline 6 & 11 days & T.A.P.V.D. 6 to hepatic vein & Atrial flutter & $\begin{array}{l}\text { Death (primary } \\
\text { lesion) }\end{array}$ \\
\hline 7 & $6 \mathrm{mth}$. & Ostium primum A.S.D. ${ }^{7}$ & Atrial flutter & $\begin{array}{l}\text { Death (quinidine } \\
\text { intoxication) }\end{array}$ \\
\hline 8 & $2 \mathrm{yr}$. & T.A.P.V.D. 6 to coronary sinus & Atrial flutter & $\begin{array}{l}\text { Death (cerebral } \\
\text { anoxia) }\end{array}$ \\
\hline 9 & $14 \mathrm{yr}$. & Mitral stenosis & Atrial fibrillation & Recovery \\
\hline \multicolumn{5}{|c|}{ B: Complications of angiography } \\
\hline 10 & 12 mth. & P.V.S. 3 & $\begin{array}{l}\text { Retrograde injection into coronary } \\
\text { sinus; circulatory collapse }\end{array}$ & Recovery \\
\hline 11 & 4 wk. & Double outlet right ventricle & $\begin{array}{l}\text { Cerebral œdema following venous } \\
\text { angiocardiogram }\end{array}$ & Death \\
\hline 12 & $8 \mathrm{mth}$. & T.A.P.V.D. 6 to superior cava & $\begin{array}{l}\text { Cerebral œedema following left atrial } \\
\text { injection }\end{array}$ & Death \\
\hline 13 & $6 \mathrm{yr}$. & Possible Cushing's syndrome & Convulsions following aortogram & Death \\
\hline 14 & 4 yr. & $\begin{array}{l}\text { Intercostal arteriovenous } \\
\text { fistula }\end{array}$ & $\begin{array}{l}\text { Cerebral odema following aortogram; } \\
\text { transient hemiparesis }\end{array}$ & Recovery \\
\hline 15 & $3 \mathrm{mth}$. & $\begin{array}{l}\text { Anomalous origin of left } \\
\text { coronary artery from pul- } \\
\text { monary artery }\end{array}$ & $\begin{array}{l}\text { Cardiac arrest following left ventriculo- } \\
\text { angiogram }\end{array}$ & Death \\
\hline 16 & $8 \mathrm{yr}$. & Fallot's tetrad & $\begin{array}{l}\text { Transient hemiparesis following selec- } \\
\text { tive angiocardiography }\end{array}$ & Recovery \\
\hline 17 & 3 wk. & $\begin{array}{l}\text { Complete transposition of } \\
\text { great vessels }\end{array}$ & $\begin{array}{l}\text { Inferior vena caval thrombosis (prob- } \\
\text { ably unrelated to catheterization) }\end{array}$ & Death \\
\hline 18 & 3 wk. & $\begin{array}{l}\text { Complete transposition of } \\
\text { great vessels }\end{array}$ & $\begin{array}{l}\text { Sagittal sinus thrombosis (probably } \\
\text { unrelated to catheterization) }\end{array}$ & Death \\
\hline \multicolumn{5}{|c|}{ C: Complications probably due to embolism } \\
\hline 19 & $15 \mathrm{mth}$. & Tricuspid atresia & $\begin{array}{l}\text { Transient hemiparesis following left } \\
\text { ventricular injection }\end{array}$ & Recovery \\
\hline 20 & $9 \mathrm{yr}$. & $\begin{array}{l}\text { Isolated drainage of I.V.C. } 8 \text { to } \\
\text { left atrium }\end{array}$ & $\begin{array}{l}\text { Severe cerebral damage } \\
\text { Permanent hemiplegia }\end{array}$ & Recovery \\
\hline
\end{tabular}

1 V.S.D. : Ventricular septal defect

2 P.D.A. : Patent ductus arteriosus

3 P.V.S. : Pulmonary valve stenosis

4 P.F.O. : Patent foramen ovale

5 A.R. : Aortic regurgitation.

6 T.A.P.V.D.: Total anomalous pulmonary venous drainage

7 A.S.D. : Atrial septal defect

8 I.V.C. : Inferior vena cava 
had very severe pulmonary valvular stenosis, and the cause of death was never determined; this patient has been omitted from the Table which summarizes the significant complications observed since 1954. Two infants with complete transposition of the great vessels (Cases 17 and 18) died following catheterization with major venous thromboses probably unrelated to the investigatory procedure.

\section{COMPlications Related to CATHETERIZATION ITSELF}

The complications related to the passage of catheter are due to trauma to the vessel used to introduce the catheter or to the heart itself, and to breakage, knotting, or impaction of the catheter, all of which will interfere with its removal. Occasionally also the catheter will obstruct blood flow through a normal or stenotic pathway. Trauma to the entry vessel may result either in local thrombosis or in perforation. The effects of this will depend on whether a vein or artery is concerned.

Significant local venous thrombosis is uncommon. We have had only two cases.

Case 1. An axillary vein thrombosis followed withdrawal of a looped catheter into the axillary vein in a girl aged 4 years with ventricular septal defect and patent ductus arteriosus.

Case 2. Femoral vein thrombosis followed unexplained difficulty in withdrawing a catheter through the junction of long saphenous and femoral veins in an infant aged 6 months. This infant, who had severe pulmonary valve stenosis with right-to-left shunt through the foramen ovale, then developed a hemiplegia, presumably from paradoxical embolism. The hemiplegia has persisted.

Problems do not usually follow ligation of the veins used for catheterization. These veins are ordinarily the median cubital vein or the long saphenous vein in the groin. In infants it is sometimes necessary to introduce the catheter directly into the femoral vein which is subsequently

ligated. There is temporary evidence of venous

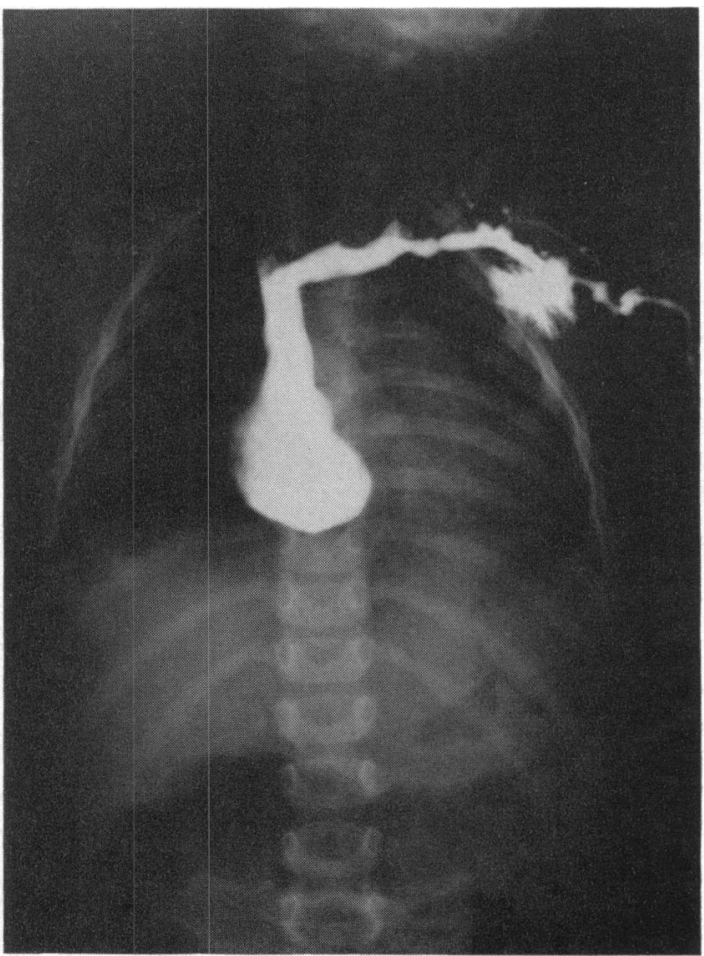

Fig. 1.-Extravasation of dye into the axilla. obstruction but no more serious problems have been observed.

The incidence of peripheral venous perforation is uncertain.

Case 3. We are aware of one case of axillary vein perforation in a child aged 26 months, due to difficulty in passing the catheter into the thorax from the axillary vein, and demonstrated by extravasation of dye into the axilla during subsequent venous angiocardiography (Fig. 1).

There has been no evidence of femoral artery thrombosis following percutaneous catheterization, recently reported as a complication of this procedure (Bell, 1962). The patients described in that report were, however, all adults.

We have had only one case of arterial perforation.

Case 4. Accidental perforation of the iliac artery by the Seldinger guide wire occurred in a boy aged 13 years with ventricular septal defect and aortic regurgitation. A retroperitoneal hæmatoma resulted.

Case 5. Another patient with virtual pulmonary atresia and ventricular septal defect bled from the femoral artery puncture following arterial catheterization performed using a Seldinger needle passed through the wound used for catheterization of the long saphenous vein. Ligation of the femoral artery 
was necessary to control the bleeding. There were no complications. In this boy, who was grossly cyanotic, bleeding was related to severe thrombocytopenia.

Trauma to the heart may lead to perforation of that organ with consequent tamponnade as recently described by Lurie and Grajo (1962) in 4 small infants. We have not had such an experience. Local damage to the myocardium without perforation but with fatal consequences has also been described (Goodwin, 1953; Scebat et al., 1957).

Minimal trauma must be held responsible for the disturbances of rhythm and conduction not infrequently observed during catheterization. As already mentioned extrasystoles regularly occur as the catheter enters the right ventricle and as it lies in the right ventricular outflow tract. These transient extrasystoles are of no great importance. Episodes of supraventricular tachycardia, usually fairly brief, occur at times, as do conduction defects consisting either of right bundle-branch block or atrioventricular dissociation. Spontaneous return of sinus rhythm or normal conduction usually occurs relatively quickly once the catheter has been withdrawn from the heart. Supraventricular tachycardia can be terminated at times by passing the catheter into the right ventricle and stimulating ventricular extrasystoles.

Occasionally arrhythmia will persist after catheter study or will recur. We have had 4 patients in which troublesome arrhythmia persisted or recurred. Atrial flutter developed in 3 patients with serious underlying cardiac disease of developmental origin, while atrial fibrillation developed in one patient with mitral stenosis. Sinus rhythm was restored in three of these patients. One of the three died as a result of cerebral damage from impaired cardiac output due to the arrhythmia, and the underlying condition proved lethal in another.

The ventricular rate seen in infants with atrial flutter deserves comment. In infancy the common supraventricular tachycardia presents with a regular ventricular rate at between 250 and 300 beats a minute. In flutter a somewhat irregular ventricular response occurs at a rate of approximately 200 beats a minute. An arrhythmia of this type and rate should always arouse suspicion of the onset of atrial flutter.

Case 6. A newborn baby with obstructed total anomalous pulmonary venous drainage through the diaphragm to the ductus venosus and thence to the hepatic veins developed atrial flutter during catheterization. The baby was then aged 11 days. The arrhythmia persisted and led to development of cardiac failure, the baby previously having been very ill with severe pulmonary œdema. The flutter was terminated with small doses of quinidine but the baby died 7 days after the catheterization as a result of the underlying anomaly.

Case 7. An infant aged 6 months with cardiac failure due to an ostium primum defect with mitral and tricuspid valve abnormalities and associated with pulmonary hypertension developed atrial flutter that persisted after catheterization. This arrhythmia proved intractable. The baby ultimately died from quinidine toxicity when the drug dosage was being increased in an attempt to terminate the flutter and to restore sinus rhythm.

Case 8. A child aged 2 years, with total anomalous pulmonary venous drainage to the coronary sinus, developed atrial flutter while being catheterized. The flutter ceased before the child returned to the ward but recurred in a few hours. There was gross circulatory impairment and although sinus rhythm was restored about four hours later death occurred from respiratory failure due to anoxic brain damage.

Case 9. Atrial fibrillation developed during catheterization in a boy aged 14 years, who had previously had mitral valvotomy for tight mitral stenosis complicated by severe pulmonary hypertension. Sinus rhythm was restored post-operatively with quinidine after preliminary digitalization.

We have had no episode of serious ventricular arrhythmia such as fibrillation. This may occur not only simply from the mechanical effect of the catheter but also by inadvertent electrical stimulation of the myocardium. This danger has recently been discussed in relation to intracardiac electrodes by Burchell (1961).

Catheters fortunately usually break outside the point of entry to the vein being used, since it is here that the maximum rotational strain is applied. Breakage is therefore usually of no consequence. Scebat et al. (1957) report an unusual case in which the distal end of a catheter broke off and remained in a lower lobe branch of the pulmonary artery without complication. We have 
not observed knotting of the catheter as has been described (Kjellberg et al., 1959; Scebat et al., 1957; Sones, 1955).

On several occasions anxiety has been caused by impaction of the catheter in a pulmonary vein preventing withdrawal of the tip into the left atrium and back through the foramen ovale. The catheter has ultimately been disimpacted by prolonged careful traction.

Obstruction of blood flow by the catheter is particularly liable to occur in cases of severe pulmonary valve stenosis without ventricular septal defect. It is well known that considerable anoxia may occur in such cases when the catheter passes through the stenotic valve orifice into the pulmonary trunk. This is manifest initially by the onset of bradycardia. The pulmonary artery pressure tracing inevitably becomes artefactual and the saturation obtained from that vessel is excessively low, because of the obstruction to pulmonary flow.

When an arterial catheter is passed into a coronary artery, flow through that vessel may be obstructed. This is recognized by the development of electrocardiographic evidence of myocardial ischæmia.

\section{Complications Related to Substances Intentionally InTroduced into the Cardiovascular SYSTEM}

During cardiac investigatory procedures various indicator substances and radio-opaque dyes are frequently injected through the catheter or peripherally for the purpose of indicator dilution studies and for angiography. Indicator dyes do not cause trouble when used within their specified dose ranges. Radio-opaque dyes, however, lead to difficulties in several ways. The selective injection of dye into a ventricular cavity frequently produces extrasystoles, but not usually more serious arrhythmia. Like the extrasystoles due to the passage of the catheter, these are presumably the result of minimal endocardial trauma.

A potentially more serious situation arises from the extravasation of dye into the myocardium itself, resulting from penetration of the muscle by one of the jets issuing fiom the catheter during pressure injection (Fig. 2). This may occur even when the pressure tracing obtained from the catheter before injection is normal and blood is sampled readily. We have not so far seen any serious effect from this. The dye shadow has disappeared quite quickly and there has been no clinical sequel. If, however, the patient should come to necropsy soon after the procedure, the local hæmorrhage in the myocardium may be impressive. Scarring may well occur as a result of this lesion. Dye may appear in the pericardial sac during selective angiocardiography. This event may be due to perforation of the myocardium by the catheter itself, or by a jet of dye as described. We have not observed this complication of dye injection.

Another complication, probably due simply to the effect of injection of fluid at high pressure rather than to use of dye, is that related to accidental injection of dye into the coronary sinus. This possibility should be avoided by attention to pressure tracings and to the oxygen saturation of blood samples obtained from the point where the catheter is positioned for angiography.

Case 10. A girl, aged 12 months, was thought to have pulmonary valve stenosis. Right ventricular hypertension was demonstrated but the pulmonary trunk was not entered. A bolus of $8 \mathrm{ml}$. of 70 per cent diagonal was injected into what was thought to be the right ventricle. Circulatory collapse ensued, but the baby fortunately recovered. The angiogram films showed that the dye had been injected retrogradely into the coronary sinus with widespread extravasation throughout the myocardium (Fig. 3). This baby was fortunate to survive, and the experience reinforces the need for continuous care to prevent such an event.

The most important complications of injection of radio-opaque dye are those that appear to be due to the dye itself. There are many reports of death attributable to injection of radio-opaque dye for urography and for angiography. There may be immediate collapse, often with respiratory arrest, or death may be delayed. The mechanism of these reactions remains uncertain. Allergy has been invoked but seems improbable (Sandström, 1955). Sludging of blood with small vessel obstruction has also been suggested as the basis for the observed phenomena in view of certain 


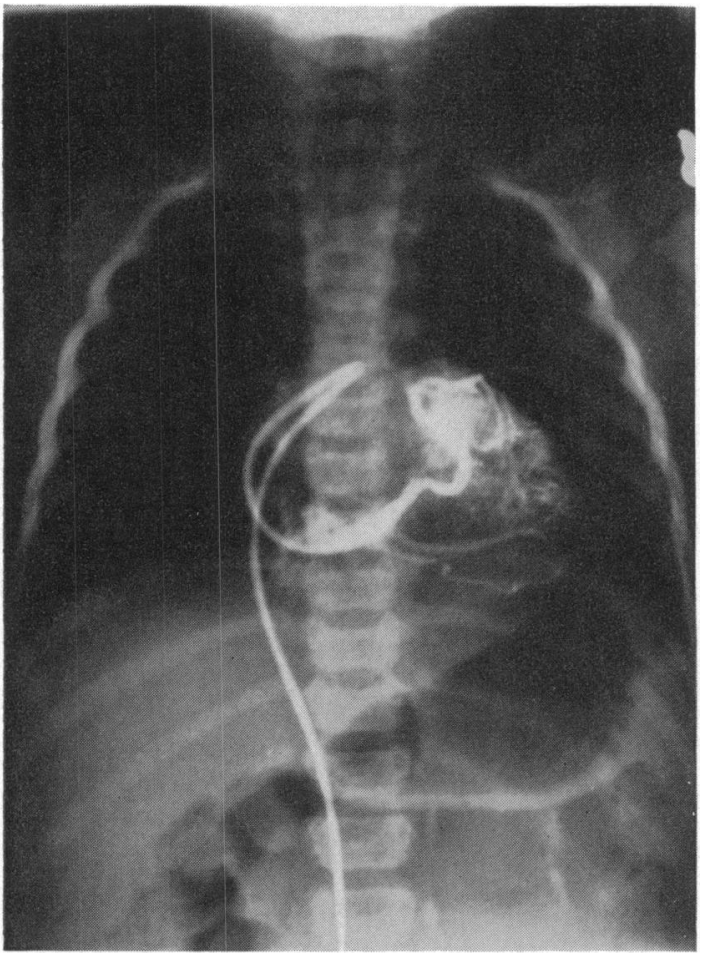

FiG. 2.-Injection of dye into the heart muscle.

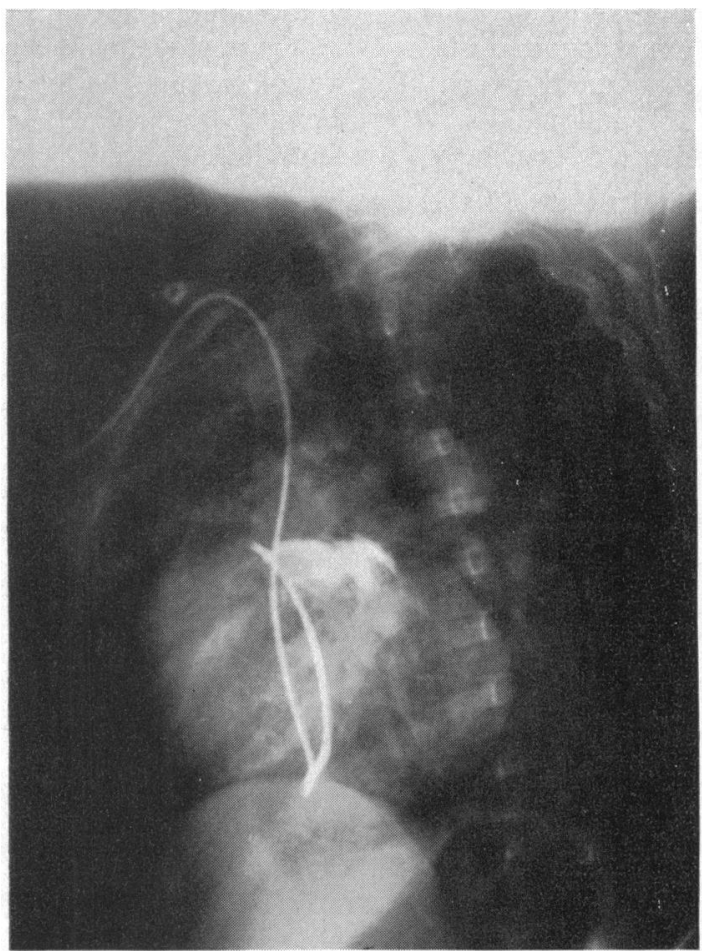

FIG. 3.-Injection of dye into coronary sinus.

clinical and experimental studies (Read and Meyer, 1959; Sobin et al., 1959). This effect is apparently shared by the radio-opaque dye with other hypertonic solutions. Direct toxic effects of excessively large local concentrations of dye may well be responsible in some cases. There is also the possibility that displacement of the blood column leads to an anoxic insult to certain organs.

We have observed no immediate "anaphylactoid" reaction to radio-opaque dye injection for angiography, either by peripheral venous or selective routes. We have, however, observed four serious reactions to dye in which the mechanism appeared to be one of local damage to the brain from the presence of dye in the cerebral vessels. In one other case dye in the coronary arterial system may well have contributed to the events that followed this injection.

Case 11. A cyanotic baby aged 4 months, who proved at necropsy to have a double outlet right ventricle without pulmonary stenosis, was studied by means of a venous angiocardiogram. The baby was thought to be satisfactory and was returned to the ward, but soon afterwards his parents observed twitching. Approximately four hours after the procedure the baby had a major convulsion and died. Necropsy revealed a brain not obviously œdematous but heavier than usual.

Case 12. A baby aged 8 months, with total anomalous pulmonary venous drainage to the superior vena cava, had a selective injection of radio-opaque dye into the left atrium. Immediately after the injection the baby began to fit and suffered temporary respiratory arrest. There was some initial response to resuscitative measures but progressive circulatory failure led to death approximately four hours after the procedure. Necropsy showed macroscopic evidence of cerebral œdema. Microscopically there was some congestion of cortical vessels.

Case 13. A child, aged 6 years, had an aortogram in the course of investigation of possible Cushing's syndrome. A generalized convulsion occurred as the child recovered from the anæsthetic. The cerebrospinal fluid pressure was found to be $350 \mathrm{~mm}$. of C.S.F. after the administration of paraldehyde. The child developed respiratory failure and died approximately eight hours after the procedure.

Case 14. A girl, aged 4 years, had an aortogram to define the site of an intrathoracic systemic arteriovenous fistula. When the child was moved after the initial positioning of the catheter, the catheter tip 
became displaced from the ascending aorta into the mouth of the innominate artery. Although this was not recognized at the time, the angiograms demonstrated that a large proportion of the dye entered the innominate artery. Recovery from anæsthesia appeared uneventful but subsequently she became unrouseable and had fits. Hypothermia was instituted with chlorpromazine and external cooling. There was evidence of hemiparesis for several days after which she gradually improved with ultimate complete recovery.

In Case 11 there was a substantial right-to-left shunt with ready access of dye to the aorta. In Cases 12,13, and 14, dye was injected into the left side of the heart or aorta. In Case 14 evidence that a large amount of the dye was directed to the cerebral circuit was provided by the angiographic record.

In all four cases there were features of cerebral damage with cerebral œdema. In the first case this was not appreciated until death was imminent. In the second case circulatory failure was prominent, presumably secondary to cerebral damage. In Case 14 active measures taken to combat cerebral œdema may well have been responsible for recovery.

These four cases form only a small percentage of all those with right-to-left shunts or left-sided lesions studied in the series. Although the basis for the events in Case 14 is clear, the reason for the onset of cerebral damage in the remaining cases, rather than in other subjects with right-to-left shunt who have been studied, is less certain. The occurrence of such catastrophes is, however, recognized. It has in fact been advocated at times that the carotid arteries should be occluded temporarily during angiocardiography in the presence of substantial right-to-left shunt. This procedure is not particularly feasible.

Whether local sludging of blood, a direct toxic effect of the dye, or anoxia is responsible seems immaterial. Performance of angiocardiography under general anæsthesia delays the recognition of these complications by suppressing the early fits and by delaying recovery of consciousness. We now perform most radio-opaque dye injections without general anæsthesia. This also removes the risk of purely anæsthetic complications.

Case 15. A girl aged 3 months with anomalous origin of the left coronary artery from the pulmonary artery was subjected to a left ventricular angiogram performed through a needle inserted percutaneously into the left ventricle. Cardiac action deteriorated immediately after the injection. The chest was opened and the pericardium incised. Blood-stained fluid escaped from the pericardial cavity. Following this the heart action improved but ventricular fibrillation ensued and resuscitation was impossible. The angiogram showed stasis of dye in a very dilated left ventricle. The relative roles of tamponnade and the direct effect of dye on the myocardium are difficult to assess.

A further complication of angiocardiography, not directly related to the dye injection, has been distant vascular thrombosis.

Case 16. A boy aged 8 years with a severe form of the tetrad of Fallot suffered a period of circulatory insufficiency immediately after selective angiography with injection of dye into the right ventricle. Subsequently he was found to have a hemiparesis that disappeared over the next few days. This boy's hæmatocrit reading was 71 per cent and his hæmoglobin level was $27.4 \mathrm{~g} . / 100 \mathrm{ml}$. Circulatory stasis with vascular obstruction superimposed on severe polycythæmia seems to have been responsible for the cerebral complication observed. Actual thrombosis may well have occurred.

Thrombosis may occur spontaneously in subjects with polycythæmia. Major venous thrombosis was found at necropsy in two other patients with considerable degrees of cyanosis who died after investigation. These thromboses were almost certainly unrelated to the investigations.

Case 17. An infant aged 3 weeks with complete transposition of the great vessels was catheterized uneventfully from the right long saphenous vein. A catheter was positioned in the right atrium for selective angiography but was inadvertently withdrawn into the inferior vena cava before dye was injected. Diversion of some of the dye to the azygos system was noted. Films of the renal areas taken following the angiographic series revealed no dye excretion. The baby died of uræmia five days after the procedure. Necropsy revealed inferior vena caval thrombosis. The infant's hæmoglobin level is not known. The diversion of dye to the azygos system, and the impaired renal function, suggested that there was already renal vein thrombosis and some inferior vena caval involvement at the time of the investigatory procedure. Histologically the thrombus in the renal vein appeared to be older than that in the inferior vena cava. 
Case 18. An infant aged 25 days, with complete transposition of the great vessels, died suddenly within a few hours of uneventful catheterization and angiography. Necropsy revealed the presence of sagittal sinus thrombosis that appeared on histological grounds to have preceded the angiogram.

The question that arises particularly from Case 15 is whether cyanotic children with high hæmatocrit levels should be venesected as a prophylactic measure against thrombosis, independently of investigations or surgical procedures that may be planned.

\section{Accidental Introduction of Undesirable Elements into Cardiovascular System}

Within this category one must include infection, air embolism, and the liberation of blood clot from the catheter. Intravascular infection is prevented by the use of aseptic techniques. Provided these are enforced antibiotic cover is not necessary. We have observed no case of intravascular infection complicating catheterization or angiography. Air embolism must always be a potential hazard when injections are made under high pressure from metal syringes through catheter systems. It is avoided by the deliberate construction of syringes so that air is readily and fully expelled during filling. Liberation of clot into the blood stream from the catheter probably occurs from time to time during catheterization. In the absence of right-to-left shunt the clots lodge in the lungs and escape notice. The continuous slow infusion of saline through the catheter, the maintenance within the catheter of a column of heparin saline solution, and heparinization of the patient are all aimed, when used, at preventing clot formation and subsequent embolism.

We have experience of two patients in whom clot embolism may well have been responsible for observed complications of the investigatory procedure.

Case 19. An infant, aged 15 months, with tricuspid atresia was subjected to cardiac catheterization. Selective angiography was performed from the left ventricle. She was discharged home apparently well but over the next few days was noticed by her parents to have weakness of one arm. The arm and hand appeared normal at her follow-up visit.

Case 20. A girl, aged 9 years, with isolated drainage of the inferior vena cava into the left atrium, was catheterized simultaneously from arm and leg under local anæsthesia. Radio-opaque dye was then injected under general anæsthesia. The leg catheter used for injection was found to have entered the azygos system from the inferior vena cava. As a result all the dye injected was carried to the right atrium and thence to the lungs. The girl failed to recover consciousness when expected and was found to have signs referable to midbrain damage. There was no evidence of cerebral œedema. Recovery was slow and incomplete with persisting hemiplegia. There was no evidence to support anoxia or dye reaction as the cause of the cerebral complication. Liberation of clot from the catheter into the inferior vena cava during the final manipulation seems almost certainly responsible. This case is being reported in full elsewhere.

\section{Discussion}

The complications are largely restricted to three situations: catheterization of sick infants, catheterization and angiocardiography in the presence of significant right-to-left shunt, and procedures in the systemic circuit. Right heart studies in children without right-to-left shunt carry minimal risks.

Cerebral complications are the most important since they are often lethal or leave serious residual disability that interferes with the result of the most successful cardiac surgery. These cerebral complications are due to thrombo-embolism, to cerebral vascular occlusion conditioned by severe polycythæmia, to embolism of clot from the catheter, or to the direct effect of radio-opaque dyes on the cerebral circuit. All these events are dependent on the presence of right-to-left shunt or on leftsided catheter manipulations.

The greatest care must be taken under such circumstances. Venesection of very polycythæmic patients before study has already been referred to. Other special precautions that might be taken are heparinization, and the prophylactic injection of low molecular weight dextrans. There is some experimental and clinical evidence (Bernstein et al., 1961) to support the proposition that low molecular weight dextrans protect against the toxic action of intravenous hypaque (sodium diatrizoate). 
Premedication with low molecular weight dextran appears to permit administration of larger doses of hypaque by increasing the lethal dose. Whether this would prevent the occasional cerebral complication of the type described is not proven, and the matter requires further study.

The actual radio-opaque dye used may well be important. In general it is probably wise to use more dilute, less irritant dyes in the systemic circuit provided adequate opacification is obtainable. It is important, however, that the techniques used give the information required from the procedure.

The need for productivity and reliability applies generally to all special cardiac investigations. It is essential that investigators command completely and use efficiently and safely sufficient techniques to enable the accurate elucidation of the problems they tackle. Command of these techniques implies not only skill in their performance, but also awareness of their limitations. Furthermore, investigatory techniques must be guided by and interpreted with sound clinical judgement.

The hazards presented are numerically small but may bring considerable danger to the patient who experiences them. They impose great responsibility on those in charge of cardiovascular diagnostic units to ensure that investigations are carried out productively and on sound indications.

\section{SUMMARY}

A review is presented of the significant complications of special cardiac investigations experienced by a pædiatric cardiac investigatory unit during a period of eight years. Six deaths resulting from such procedures are reported. Two deaths resulted from arrhythmia and four were associated with injection of radio-opaque dye.

The importance of cerebral complications of various types is discussed. Cerebral complications arising in the presence of right-to-left shunt and with manipulations in the systemic circuit are described. The hazards of investigation of sick infants with serious congenital heart disease are also stressed.

\section{REFERENCES}

Bagger, M., Biörck, G., Bjorck, V. O., Brodén, B., Carlgren, L. E., Carlsten, A., Elder, I., Ejrup, B., Eliasch, H., Gustafson, A., Gyllenswärd, Å., Hanson, H. E., Holmgren, A., Idbohrn, H., Johnsson, S. R., Jonsson, B., Jönsson, G., Karnell, J., Kjellberg, S. R., Krook, H., Larsson, H., Lindén, L., Linder, E., Linderholm, H., Lodin, H., Malmström, G., Mannheimer, E., Möller, T., Philipsson, J., Radner, S., Rudhe, U., Ström, C., Söderholm, B., Ulfsparre, F., and Werkö, L. (1957). On methods and complications in catheterisation of heart and great vessels with and without contrast injection. Amer. Heart J., 54, 766.

Bell, J. W. (1962). Treatment of post-catheterisation arterial injuries: use of survey plethysmography. Ann. Surg., $155,591$.

Bernstein, E. F., Evans, R. L., Blum, J. A., and Avant, R. F. (1961). Further experimental and early clinical observations concerning the protection action of low molecular weight dextran upon intravenous hypaque toxicity. Radiology, 76, 260.

Burchell, H. B. (1961). Hidden hazards of cardiac pacemakers. Circulation, 24, 161.

Cournand, A., Bing, R. J., Dexter, L., Dotter, C., Katz, L. N., Warren, J. V., and Wood, E. H. (1953). Report of Committee on cardiac catheterisation and angiocardiography of the American Heart Association. Circulation, $7,769$.

Goodwin. J. F. (1953). Fatality following cardiac catheterization injury. Brit. Heart J., 15, 330.

Keith, J. D., Rowe, R. D., and Vlad, P. (1958). Heart Disease in Infancy and Childhood. Macmillan, New York.

Kjellberg, S. R., Mannheimer, E., Rudhe, U., and Jonsson, B. (1959). Diagnosis of Congenital Heart Disease. The Year Book Publishers, Chicago.

Lurie, P. R., and Grajo, M. Z. (1962). Accidental cardiac puncture during right heart catheterisation. Pediatrics, $29,283$.

Read, R. C., and Meyer, M. (1959). The role of red cell agglutination in arteriographic complications. Amer. Coll. Surg. Surg. Forum, 10, 472.

Sandström, C. (1955). Secondary reactions from contrast media and the allergy concept. Acta radiol. Stockh., 44, 233.

Scebat, L., Renais, J., Meeus-Bithe, L., and Lenègre, J. (1957). Accidents, indications et contre-indications du cathétérisme des cavités droites du cour. Arch. Mal. Cour, 50, 943.

Sobin, S. S., Frasher, W. G., Jacobson, G., and Van Eeckhoven, F. A. (1959). Nature of adverse reactions to radiopaque agents. J. Amer. med. Ass., 170, 1546.

Sones, F. M., Jr. (1955). Heart catheterisation in infancy. Pediatrics, 16, 544. 